\title{
Cystatins as Calpain Inhibitors: Engineered Chicken Cystatin- and Stefin B-Kininogen Domain 2 Hybrids Support a Cystatin-Like Mode of Interaction with the Catalytic Subunit of $\mu$-Calpain
}

\author{
Beatriz García Díaz ${ }^{1,2,3}$, Stefan Gross ${ }^{1,3}$, \\ Irmgard Assfalg-Machleidt ${ }^{3}$, Dietmar Pfeiler ${ }^{1,3}$, \\ Nicole Gollmitzer ${ }^{1,3}$, Dusica Gabrijelcic-Geiger ${ }^{1}$, \\ Milton T. Stubbs ${ }^{4}$, Hans Fritz', Ennes A. \\ Auerswald ${ }^{1, a}$ and Werner Machleidt ${ }^{3, *}$ \\ ${ }^{1}$ Abteilung für Klinische Chemie und Klinische \\ Biochemie, Chirurgische Klinik Innenstadt, Klinikum der \\ Ludwig-Maximilians-Universität, Nußbaumstr. 20, \\ D-80336 München, Germany \\ 2 Departamento de Bioquímica, Facultad de Biología, \\ Universidad de la Habana, Calle 25 entre J e I Vedado, \\ Ciudad de la Habana, Cuba \\ ${ }^{3}$ Adolf-Butenandt-Institut für Physiologische Chemie, \\ Physikalische Biochemie und Zellbiologie der \\ Ludwig-Maximilians-Universität, Schillerstr. 42, \\ D-80336 München, Germany \\ ${ }^{4}$ Institut für Pharmazeutische Chemie, Philipps- \\ Universität Marburg, Marbacher Weg 6, D-35037 \\ Marburg, Germany \\ ${ }^{*}$ Corresponding author
}

Within the cystatin superfamily, only kininogen domain 2 (KD2) is able to inhibit $\mu$ - and $\mathrm{m}$-calpain. In an attempt to elucidate the structural requirements of cystatins for calpain inhibition, we constructed recombinant hybrids of human stefin $B$ (an intracellular family 1 cystatin) with KD2 and $\Delta$ L110 deletion mutants of chicken cystatin-KD2 hybrids. Substitution of the $\mathrm{N}$-terminal contact region of stefinB by the corresponding KD2 sequence resulted in a calpain inhibitor of $K_{\mathrm{i}}=188 \mathrm{nM}$. Deletion of L110, which forms a $\beta$-bulge in family 1 and 2 cystatins but is lacking in KD2, improved inhibition of $\mu$-calpain 4- to 8-fold. All engineered cystatins were temporary inhibitors of calpain due to slow substrate-like cleavage of a single peptide bond corresponding to Gly9-Ala10 in chicken cystatin. Biomolecular interaction analysis revealed that, unlike calpastatin, the cystatin-type inhibitors do not bind to the calmodulin-like domain of the small subunit of calpain, and their interaction with the $\mu$-calpain heterodimer is completely prevented by a synthetic peptide comprising subdomain B of calpastatin domain 1. Based on these results we pro-

\footnotetext{
a Present address: Klinik und Poliklinik für Neurologie, Marchioninistr. 15, D-81377 München, Germany
}

pose that (i) cystatin-type calpain inhibitors interact with the active site of the catalytic domain of calpain in a similar cystatin-like mode as with papain and (ii) the potential for calpain inhibition is due to specific subsites within the papain-binding regions of the general cystatin fold.

Key words: Calpastatin/Kininogen/Papain / Stefin B/ Surface plasmon resonance/Temporary inhibition.

\section{Introduction}

The two ubiquitous calpains, $\mu$-calpain and m-calpain, are intracellular, $\mathrm{Ca}^{2+}$-dependent cysteine proteinases that have been implicated in many important cellular functions and various pathologies (see Sorimachi et al., 1997; Carafoli and Molinari, 1998; Suzuki and Sorimachi, 1998 for recent reviews). They consist of distinct (yet homologous) large (L-)subunits (80 kDa) und a common small (S-)subunit (30 kDa). On the basis of sequence comparisons, the L-subunit has been predicted to contain four and the S-subunit two domains. Whereas the catalytic domain (domain II) of the L-subunit shows a weak sequence homology to papain, both the L-subunit and the $\mathrm{S}$-subunit contain a $\mathrm{Ca}^{2+}$-binding calmodulin-like domain (CaMLD). Until recently, only three-dimensional structures of the L-CaMLD were known (Blanchard et al., 1997; Lin et al., 1997), and hypotheses on the molecular mechanisms of activation and inhibition of calpains have been contradictory. Meanwhile, two groups have published crystal structures of the $\mathrm{Ca}^{2+}$-free, inactive form of $\mathrm{m}$-calpain, revealing the molecular architecture of this multidomain protein (Hosfield et al., 1999; Strobl et al., 2000). In these structures, the catalytic domain (II) appears disrupted into two subdomains (Ila and Ilb), explaining the inactivity of calpain in the absence of calcium. Activation should involve a 'fusion' of the two subdomains, leading to a functional papain-like catalytic domain (Hosfield et al., 1999; Strobl et al., 2000). As long as the structure of a $\mathrm{Ca}^{2+}$-activated calpain is not known, a number of questions concerning the molecular mechanisms of interaction with substrates and inhibitors remain open.

$\mathrm{Ca}^{2+}$-activated $\mu$ - and $\mathrm{m}$-calpain are controlled by a very specific intracellular protein inhibitor, calpastatin. Calpastatin contains four repeats of the inhibitory unit, each of which can inhibit calpain independently, but is not able to inhibit other cysteine proteinases of the papain superfamily (Maki et al., 1987; Emori et al., 1988). 
Conversely, calpain is not inhibited by most cystatins (Crawford, 1987), the only exceptions being the kininogens. The second cystatin-like kininogen domain (KD2) was shown to be responsible for calpain inhibition (Salvesen et al., 1986). Whereas the interaction of calpain with calpastatin has been studied in some detail (Takano et al., 1995), the interaction between calpains and kininogens remains to be investigated.

No relation can be found between cystatins and calpastatin on the basis of sequence homology. They possess a well defined three-dimensional structure (Turk and Bode, 1991), in contrast to the proposed disordered structure of calpastatin domains (Uemori et al., 1990). While attempting to identify the structural requirements for calpain inhibition by cystatins, we have shown earlier that substitution of the three chicken cystatin contact regions ( $\mathrm{N}$-terminal trunk, first and second hairpin loop) by the corresponding KD2 sequences in a single and combined manner resulted in up to 1000-fold improved calpain inhibition (Auerswald et al., 1996). However, inhibition of $\mathrm{m}$-calpain by these chimeric proteins was found to be temporary. In the present work, we investigate the mechanism of temporary inhibition of $\mu$-calpain by chicken cystatin-KD2 hybrids and the potential reasons for it. The second disulphide loop (Cys95-Cys115) of chicken cystatin is extended by one leucine residue (L110) as compared to the corresponding sequence in KD2 (see Figure 1); L110 forms a $\beta$-bulge of the terminal $\beta$-sheet that is conserved in family 1 and 2 cystatins (Bodeet al., 1988; Stubbs et al., 1990). This difference could be responsible for non-optimal binding of the chicken cystatin-KD2 hybrids to calpain resulting in temporary inhibition. In order to test our hypothesis we constructed chicken cystatin-KD2 $\Delta \mathrm{L} 110$ deletion mutants and compared them with the corresponding full-length chicken cystatin-KD2 hybrids.

Furthermore, we attempt to clarify whether calpain inhibition by engineered cystatins requires a family 2 (chicken cystatin) scaffold or is rather due to the presence of calpain-binding sequences (as in KD2) on any cystatin fold. For this purpose we constructed cystatin-KD2 hybrids using as parent molecule a member of family 1 of the cystatin superfamily, human stefin B. Like all family 1 members, stefin B conserves the general architecture of cystatins but, in contrast to chicken cystatin or KD2, occurs intracellularly and lacks disulphide bridges. Stefin B has a shorter N-terminal 'trunk' and a wider second hairpin loop than chicken cystatin (Stubbs et al., 1990).

The interaction of the chimeric inhibitors with human $\mu$-calpain and with a recombinant fragment of its small subunit was studied by real time biomolecular interaction analysis using surface plasmon resonance technology. A hypothesis is presented on the mode of interaction of calpain with cystatin-type protein inhibitors and is compared with the present knowledge on its interaction with calpastatin.

\section{Results}

\section{Gene Design for the Chimeric Proteins}

Figure 1 shows the amino acid sequences of the engineered proteins compared with those of the parent proteins. The $\Delta$ Leu110 chicken cystatin-KD2 hybrids were prepared from the corresponding chicken cystatin-KD2

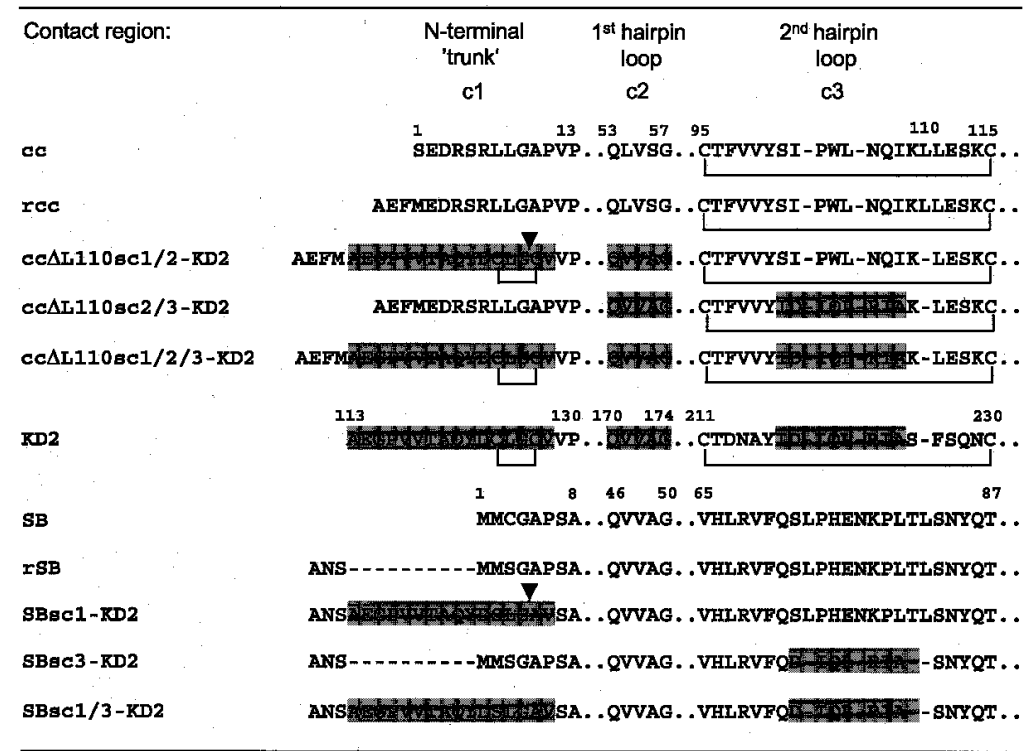

Fig. 1 Scheme of the Chicken Cystatin- and Stefin B-Kininogen Domain 2 Hybrids.

The contact regions of stefin B and chicken cystatin with papain (c1, c2, c3) were substituted by the corresponding sequences of human kininogen domain 2 (grey) in a single and combined manner (hybrids sc1, sc3, sc1/2, sc1/3, sc1/2/3). cc, natural chicken cystatin; rcc, recombinant chicken cystatin (AEF-[M1, 129, L89] chicken cystatin); KD2, kininogen domain 2; SB, natural stefin B; rSB, recombinant stefin $B ; \Delta L 110$, Leu110 deletion mutant of cc. The sequences of chicken cystatin and stefin B were aligned according to topological equivalence in tertiary structure (Stubbs et al., 1990). The peptide bonds cleaved during temporary inhibition of $\mu$-calpain are marked by arrowheads. 

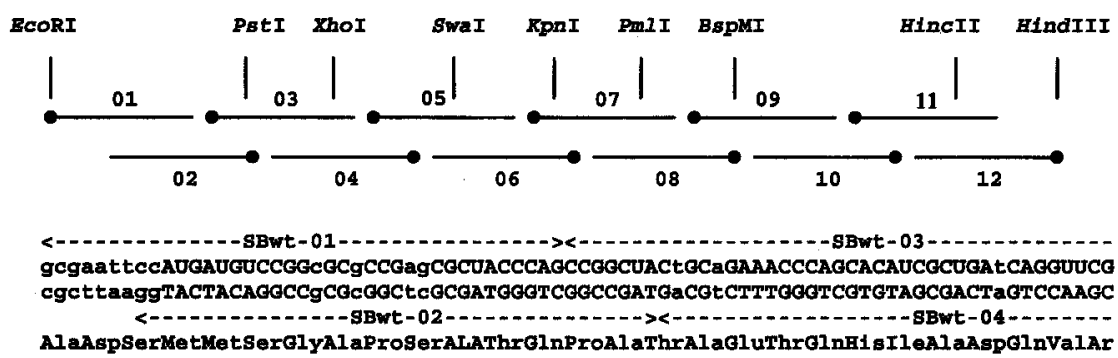

AlaAspSerMetMetSerGlyAlaProSerALAThrOlnPrOAl aThrAlaGluThrGlnHisIl eAlaAspGlnValAr

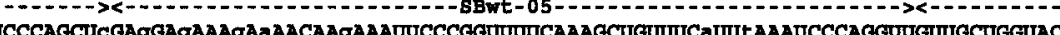
JCCCAOCUEGAgGAgAAAgAaAACAAgAAAUUCCCGOUUUDCAAAGCUGUUUCAUU LAAAUCCCAOGUUGUUGCUGGUAC AGGGTCOAGCTCCTCTTTCTETTGTTCTTIAAGGGCCAAAAGTTTCGACAAAGTAAaTTTAGGGTCCAACAACGACCATG SerGlnLeuGluGluLysGluAsnLysiysPheProValPheLy GAlaValserPheLysSerGlnValvalalaGlyTh

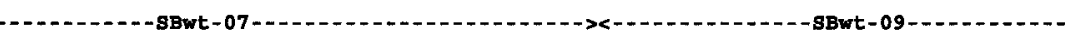
AaCUACUUCAUCAAAGUUCACGUgGGUGA COAAGA UUUCOUUCA CCUGCGUGUUUUCCAGUCCCUGCCGCA CGAAAACAA TTGATGAAGTAGTPTCAAGTGCACCCACTGCTTCTGAAGCAAGTGGACGCACAAAAGGTCAGGGACGGCOTGCTTTTCTT

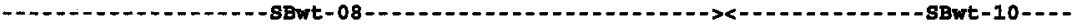
AsnTyrPheIl eLYsValHi sValGlyAspGluAspPheValHisLeuArgValPheolnserLeuProHAsGluAsnty

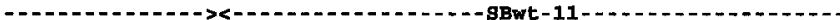

CCOCUGACCCUGUCCAACUACCAGACCAACAAAGCUAAgCACGACGAgtUGACCUACUUCtagt

GGCGACTGGGACAGGTTATGGTCTGGTTGTTTCGATTCGTGCTGCTCAACTGGATGAAGatcat tcg

(12-10

ProLeuThrLeuSerAsnTyrolnThrAsnLysAlaLyshisAspGluLeuThrTyrPhe* *

Fig. 2 Synthetic Gene Encoding Human Stefin B.

The upper panel shows the construction of the synthetic gene from 12 individual oligonucleotides (numbered lines) and the distribution of unique restriction sites. The complete DNA and amino acid sequences of ANS-[C3S]-r-stefin B are presented in the lower panel.

hybrids described earlier (Auerswald et al., 1996) by PCR mutagenesis and ligated into the expression vector pIN-III-ompA2 to allow periplasmic expression in E. coli. The stefin B-KD2 hybrids were constructed following the same general strategy as described previously for the chicken cystatin-KD2 hybrids (Auerswald et al., 1996). Three stefin B-KD2 hybrids were designed, carrying the putative contact regions $\mathrm{c} 1$ ( $\mathrm{N}$-terminus) and c3 (second hairpin loop) of KD2 in a single and combined manner. Since contact region $\mathrm{c} 2$ (first hairpin loop) of stefin $\mathrm{B}$ and KD2 are identical, further substitutions were not necessary. A synthetic gene for stefinB (Figure 2) was designed and assembled from twelve oligonucleotides according to the method of Khorana (1979). The single cysteine residue in stefin $B$ (Cys3) was substituted by serine in order to avoid dimerisation via disulphide bridges. The hybrids were then constructed either by total gene synthesis or by cassette mutagenesis (see Materials and Methods for details). The insertion of an EcoRI restriction site at the 5' end of the genes for ligation into the cloning and expression vectors (pUC 18 and pASK 40) involved the introduction of the tripeptide sequence Ala-Asn-Ser(ANS-) at the $\mathrm{N}$-terminus of the recombinant proteins. Cys124 and Cys127 of the N-terminal KD2 sequence were replaced by Ser and Ala, respectively. Subcloning of the genes into the expression vector pASK 40 enabled periplasmic expression.

\section{Protein Expression, Purification and Characterisation}

The $\Delta$ Leu110 chicken cystatin-KD2 hybrids were isolated from the periplasmic fractions of the induced $E$. coli cultures and purified to $90-95 \%$ homogeneity by affinity chromatography on a carboxymethyl-papain Sepharose column followed by anionic exchange chromatography on a Mono $Q$ column (Figure 3 ). The identity of the chimeric proteins was verified by $\mathrm{N}$-terminal amino acid sequencing and mass spectrometry. Table 1 summarises the results of expression, purification and characterisation of the hybrids.

The stefin B-KD2 hybrid SBsc1-KD2 (see Figure 1 for explanation of abbreviations) was detected in $\mathrm{mg}$ amounts (estimated by Western blotting and papain in-

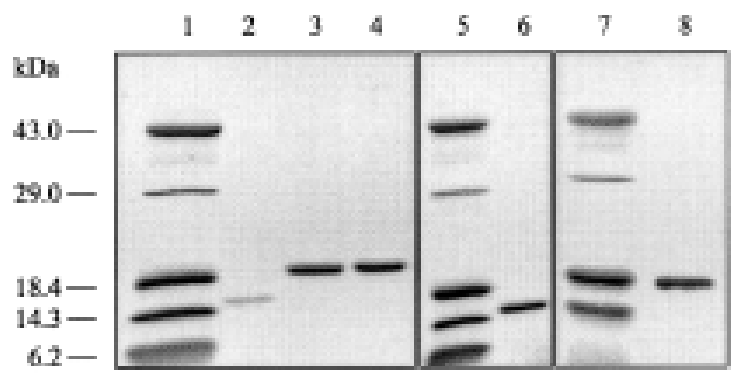

Fig. 3 SDS-PAGE of the Purified Hybrids.

Lanes 1,5,7 show low molecular mass standards. Three to five $\mu \mathrm{g}$ of purified inhibitors were applied: lane $2, \Delta \mathrm{L} 110 \mathrm{cc}$; lane 3 , $\Delta \mathrm{L} 110 \mathrm{ccsc} 1 / 2-\mathrm{KD} 2$; lane $4, \Delta \mathrm{L} 110 \mathrm{ccsc} 1 / 2 / 3-\mathrm{KD} 2 ;$ lane 6 , $\Delta \mathrm{L} 110 \mathrm{ccsc} 2 / 3-\mathrm{KD} 2$ and lane 8, SBsc1-KD2. 
Table 1 Expression, Purification and Protein Chemical Characterisation of the $\Delta$ L110 Chicken Cystatin-KD2 and Stefin B-KD2 Hybrids.

\begin{tabular}{llllll}
\hline Hybrida & $\begin{array}{l}\text { Expression } \\
{[\mathrm{mg} /]^{\mathrm{b}}}\end{array}$ & $\begin{array}{l}\text { Purification } \\
{[\mathrm{mg} /]^{\mathrm{b}}}\end{array}$ & N-terminal sequence & $\begin{array}{l}\text { Molecular mass } \\
{[\mathrm{Da}]}\end{array}$ \\
\hline$\Delta \mathrm{L} 110 \mathrm{cc}$ & 3.5 & 1.6 & AEFME & $>95 \%$ & 13386.1 \\
$\Delta \mathrm{L} 110 \mathrm{ccsc} 1 / 2-\mathrm{KD} 2$ & 3.2 & 1.6 & $\mathrm{AEF}$ & $>95 \%$ & 13865.9 \\
$\Delta \mathrm{L} 110 \mathrm{ccsc} 2 / 3-\mathrm{KD} 2$ & 0.8 & 0.3 & $\mathrm{AEF}$ & $>95 \%$ & 13327.0 \\
$\Delta \mathrm{L} 110 \mathrm{ccsc} 1 / 2 / 3-\mathrm{KD} 2$ & 2.0 & 0.8 & AEFMAEG & $>90 \%$ & 13838.7 \\
$\mathrm{SBsc1-KD2}$ & 5.5 & 1.5 & ANSAEGPV & $>95 \%$ & 12379.7 \\
\hline
\end{tabular}

a See Figures 1 and 6 for abbreviations.

${ }^{b} \mathrm{mg}$ of active inhibitor per litre of $E$. coli cell culture.

Table 2 Equilibrium Dissociation Constants $\left(K_{i}\right)$ and Rate Constants $\left(k_{\mathrm{on}}, K_{\mathrm{off}}\right)$ of the Complexes of the Inhibitors with Different Cysteine Proteinases.

\begin{tabular}{|c|c|c|c|c|c|c|c|}
\hline \multirow[t]{2}{*}{ Inhibitor } & \multicolumn{3}{|c|}{ Papain } & \multicolumn{3}{|c|}{ Cathepsin L } & $\mu$-Calpain \\
\hline & $\begin{array}{l}k_{\mathrm{on}} \\
\left(\mathrm{M}^{-1} \mathrm{~s}^{-1}\right)\end{array}$ & $\begin{array}{l}k_{\text {off }} \\
\left(\mathrm{s}^{-1}\right)\end{array}$ & $\begin{array}{l}K_{\mathrm{i}} \\
(\mathrm{nM})\end{array}$ & $\begin{array}{l}k_{\mathrm{on}} \\
\left(\mathrm{M}^{-1} \mathrm{~s}^{-1}\right)\end{array}$ & $\begin{array}{l}k_{\text {off }} \\
\left(s^{-1}\right)\end{array}$ & $\begin{array}{l}K_{\mathrm{i}} \\
(\mathrm{nM})\end{array}$ & $\begin{array}{l}K_{\mathrm{i}} \\
(\mathrm{nm})\end{array}$ \\
\hline r-chicken cystatin & $1.3 \times 10^{7 b}$ & $1.8 \times 10^{-5 b}$ & $0.0014^{b}$ & $7.8 \times 10^{7 \mathrm{~b}}$ & $6.7 \times 10^{-5 b}$ & $0.0009^{b}$ & 75000 \\
\hline$\Delta \mathrm{L} 110 \mathrm{cc}$ & $2.8 \times 10^{7}$ & $1.3 \times 10^{-4}$ & 0.0046 & $5.5 \times 10^{7}$ & $3.5 \times 10^{-4}$ & 0.0064 & $920^{*}$ \\
\hline $\operatorname{ccsc} 1 / 2-K D 2$ & $3.2 \times 10^{7 b}$ & $4.1 \times 10^{-5 b}$ & $0.0013^{b}$ & $6.3 \times 10^{7 \mathrm{~b}}$ & $3.3 \times 10^{-4 b}$ & $0.0052^{b}$ & $127^{\star}$ \\
\hline$\Delta \mathrm{L} 110 \mathrm{ccsc} 1 / 2-\mathrm{KD} 2$ & $2.9 \times 10^{7}$ & $9.7 \times 10^{-5}$ & 0.0034 & $2.5 \times 10^{7}$ & $3.7 \times 10^{-4}$ & 0.0148 & $29^{*}$ \\
\hline $\operatorname{ccsc} 2 / 3-K D 2$ & $1.9 \times 10^{7 b}$ & $6.3 \times 10^{-5 b}$ & $0.0033^{b}$ & $4.0 \times 10^{7 b}$ & $1.6 \times 10^{-4 b}$ & $0.0040^{\mathrm{b}}$ & $\geq 30000$ \\
\hline$\Delta \mathrm{L} 110 \operatorname{ccsc} 2 / 3-\mathrm{KD} 2$ & $4.5 \times 10^{6}$ & $1.1 \times 10^{-4}$ & 0.0244 & $1.3 \times 10^{7}$ & $2.8 \times 10^{-4}$ & 0.0215 & $\geq 5000$ \\
\hline $\operatorname{ccsc} 1 / 2 / 3-K D 2$ & $5.8 \times 10^{6 b}$ & $2.8 \times 10^{-4 b}$ & $0.0480^{b}$ & $3.9 \times 10^{6 b}$ & $1.7 \times 10^{-3 b}$ & $0.436^{\mathrm{b}, *}$ & $380^{*}$ \\
\hline$\Delta \mathrm{L} 110 \operatorname{ccsc} 1 / 2 / 3-\mathrm{KD} 2$ & $2.9 \times 10^{6}$ & $2.0 \times 10^{-4}$ & 0.0690 & $2.8 \times 10^{6}$ & $1.2 \times 10^{-3}$ & $0.428^{\star}$ & $100^{*}$ \\
\hline $\mathrm{KD} 2$ prot & $7.3 \times 10^{6 b}$ & $1.2 \times 10^{-4 b}$ & $0.0160^{b}$ & $2.2 \times 10^{7 \mathrm{~b}}$ & $3.3 \times 10^{-4 b}$ & $0.0150^{\mathrm{b}}$ & 5.4 \\
\hline L-kininogen & $2.0 \times 10^{7 b}$ & $6.4 \times 10^{-5 b}$ & $0.0032^{b}$ & $3.0 \times 10^{7 \mathrm{~b}}$ & $1.1 \times 10^{-4 b}$ & $0.0035^{b}$ & 1.0 \\
\hline SBsc1-KD2 & $6.6 \times 10^{6}$ & $7.6 \times 10^{-5}$ & 0.0120 & $4.0 \times 10^{6}$ & $4.1 \times 10^{-5}$ & 0.0104 & $188^{*}$ \\
\hline r-stefin B & $8.9 \times 10^{6}$ & $5.7 \times 10^{-5}$ & 0.0064 & $2.1 \times 10^{7}$ & $1.8 \times 10^{-4}$ & 0.0086 & $\geq 60000$ \\
\hline
\end{tabular}

a See Figures 1 and 6 for abbreviations.

${ }^{\mathrm{b}}$ Data taken from Auerswald et al. (1996).

* Temporary inhibition.

hibitory activity) in the periplasm, whereas SBsc3-KD2 and SBsc1/3-KD2 formed inclusion bodies. The hybrid SBsc1-KD2 was purified to $95 \%$ homogeneity and characterised by SDS-PAGE (see Figure 3), reversed-phase HPLC (data not shown), N-terminal amino acid sequencing and mass spectrometry (Table 1).

\section{Inhibitory Profiles of the Hybrids}

The equilibrium dissociation constants $\left(K_{\mathrm{i}}\right)$ as well as the association and dissociation rate constants $\left(k_{\text {on }}, k_{\text {off }}\right)$ of the complexes formed between the inhibitors and different cysteine proteinases are summarised in Table 2. Inhibition of papain and cathepsin $L$ by the chicken cystatin hybrids was marginally less than that of the parent molecules; nevertheless, all hybrids remained tightbinding inhibitors of these enzymes ( $K_{\mathrm{i}}$ in the pM range), suggesting that neither deletion of the Leu110 residue in the chicken cystatin hybrids nor the $\mathrm{N}$-terminal substitution of stefin B with a KD2 sequence had essentially altered the general cystatin fold required for tight-binding interactions. On the other hand, deletion of Leu110 in the chicken cystatin hybrids resulted in a 4-5-fold improvement of calpain inhibition. While the $K_{\mathrm{i}}$ of recombinant stefin $B$ for the inhibition of $\mu$-calpain is at least 60 $\mu \mathrm{M}$, substitution of its $\mathrm{N}$-terminus by that of KD2 in the SBsc1-KD2 hybrid resulted in 300-fold improved calpain inhibition $\left(K_{\mathrm{i}}=188 \mathrm{~nm}\right)$.

\section{Temporary Inhibition of $\mu$-Calpain}

Inhibition of $\mu$-calpain by the $\Delta \mathrm{L} 110$ chicken cystatinKD2 and stefin B-KD2 hybrids was shown to be temporary. After rapid initial inhibition, the activity of calpain reappeared and increased slowly until a second stable equilibrium was reached. Figure 4 shows a typical inhibition experiment of $\mu$-calpain by $\Delta \mathrm{L} 110 \mathrm{ccsc} 1 / 2-\mathrm{KD} 2$.

The time course of the inhibition experiment can be explained by a conversion of the inhibitor into a 'modified' form of much lower affinity. This putative conversion was confirmed by SDS-PAGE and N-terminal amino acid sequencing (Figure 5). After incubation of the hybrids $\mathrm{cc} \Delta \mathrm{L} 110 \mathrm{sc} 1 / 2-\mathrm{KD} 2$ and SBsc1-KD2 with $\mu$-calpain, a second band was detected migrating at a lower apparent 


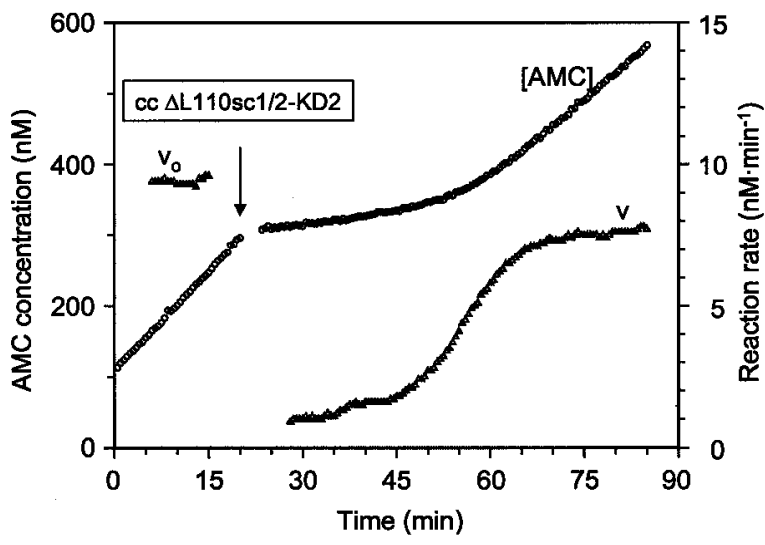

Fig. 4 Temporary Inhibition of $\mu$-Calpain by $\Delta \mathrm{L} 110 \operatorname{ccsc} 1 / 2-$ KD2.

Typical inhibition experiment showing the time course of concentration of the fluorescent reaction product (AMC, circles) and the reaction rate (triangles) calculated within a moving window of $10 \mathrm{~min}(\mathrm{v})$. After a constant reaction rate $\left(\mathrm{v}_{0}\right)$ had been obtained with $\mu$-calpain (10 nM), $\Delta$ L110ccsc1/2-KD2 (280 nM) was added (arrow).

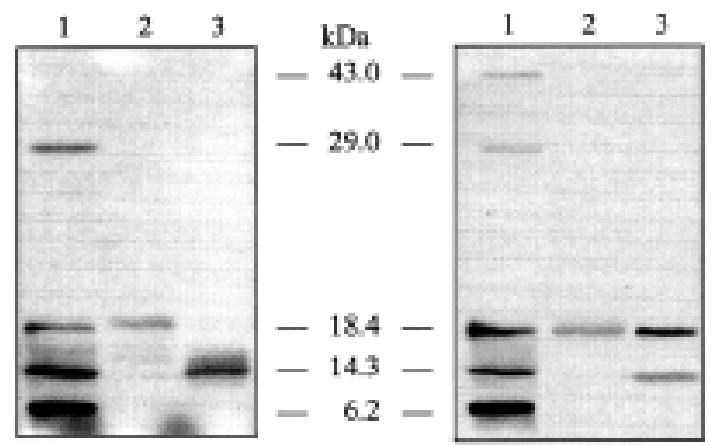

Fig. 5 Analysis of Temporary Inhibition by SDS-PAGE. $\Delta \mathrm{L} 110 \mathrm{ccsc} 1 / 2-\mathrm{KD} 2$ (left) and SBsc1-KD2 (right) were incubated with $\mu$-calpain for $90 \mathrm{~min}$. Samples taken at time 0 (lane 2) and 90 min (lane 3) were analysed by SDS PAGE and N-terminal sequencing. The new sequences found were CVVP... for $\Delta \mathrm{L} 110 \mathrm{ccsc} 1 / 2-\mathrm{KD} 2$ and $\mathrm{AVSA} . .$. for SBsc1-KD2, resulting from cleavage behind Gly18 or Gly17, respectively (see Figure 1 for the complete sequences). Lane 1, low molecular mass standards.

molecular mass. N-terminal sequencing of the incubated mixtures revealed that the conversion is due to cleavage of a single peptide bond, Gly18-Cys19 in the chicken cystatin-KD2 hybrid, and Gly17-Ala18 in the stefinB-KD2 hybrid. These bonds correspond to Gly9-Ala10 in natural chicken cystatin and Gly4-Ala5 in natural stefin B (see Figure 1) involving the Gly residue that is highly conserved within the cystatin superfamily (Turk and Bode, 1991).

\section{Biomolecular Interaction Analysis}

The chicken cystatin-KD2 hybrid cc $\Delta$ L110sc1/2-KD2and the stefin B-KD2 hybrid SBsc1-KD2 were chosen to investigate the binding of $\mu$-calpain to these cystatin-like in- hibitors and to compare it with the binding of $\mu$-calpain to recombinant inhibitory calpastatin domain 1 (rCD1; Emori et al., 1988). For real-time biomolecular interaction analysis the inhibitors were immobilised on CM5 chips via amino groups. The interaction of $\mu$-calpain with the immobilised inhibitors was analysed in the presence and in the absence of calcium. In the presence of $0.2 \mathrm{mM} \mathrm{CaCl} 2$ we observed a strong binding of $\mu$-calpain to $\mathrm{rCD} 1$; but also KD2 $2_{\text {prot }}$ (KD2 obtained by limited proteolysis of L-kininogen) as well as the $\Delta L 110$ chicken cystatin-KD2 and stefin $\mathrm{B}-\mathrm{KD} 2$ hybrids were able to bind the injected $\mu$-calpain (Figure 6A). In contrast, $\mathrm{Ca}^{2+}$-activated calpain did not bind to immobilised chicken cystatin or stefin $B$, which were used as negative controls. When $\mu$-calpain was injected in the absence of calcium, no binding to the immobilised inhibitors was observed (data not shown).

Calpastatin peptide B (CPB), a synthetic peptide of 27 amino acids comprising the minimal inhibiting unit of calpastatin domain 1, has been shown to be a competitive inhibitor and is thus supposed to bind to the active site of calpain (Maki et al., 1988; Kawasaki et al., 1989; Crawford et al., 1993). Therefore we performed competition experiments with this peptide. For complex formation, CPB was added to $\mathrm{Ca}^{2+}$-activated $\mu$-calpain $\left(0.2 \mathrm{mM} \mathrm{Ca}^{2+}\right.$ for $5 \mathrm{~min}$ ) in a molar ratio of 20:1. When the mixture was passed over the chips, only immobilised rCD1 was able to bind $\mu$-calpain, whereas the immobilised chicken cystatin-KD2 and stefin B-KD2 hybrids as well as KD2 $2_{\text {prot }}$ did not display any binding (Figure 6 B). Similarly, binding of $\mu$-calpain to the cystatin-like inhibitors was completely abolished when the activated enzyme was pre-incubated with an excess of whole rCD1 (data not shown).

It has been shown previously that the inhibitory domain 1 of calpastatin is able to bind the calmodulin-like domains of the large subunit (domain IV) and of the small subunit (domain VI) of calpain (Takano et al., 1995). Therefore we investigated the interaction of KD2 as well as of cystatin- and stefin B-KD2 hybrids with a recombinant $21 \mathrm{kDa}$ fragment containing the complete CaMLD (domain VI) of the small subunit (Figure 6C). Clearly, neither immobilised KD2 nor the immobilised chicken cystatin-KD2 and stefin B-KD2 hybrids were able to bind the $21 \mathrm{kDa}$ protein. In contrast, immobilised rCD1 exhibited a fast, strong interaction with this calpain fragment. Immediately after the described binding experiments, the immobilised inhibitors were able to bind again activated calpain and carboxymethylated papain (data not shown), proving their integrity and the validity of the results obtained.

\section{Discussion}

Due to the lack of structural information on $\mathrm{Ca}^{2+}$-activated calpain and KD2, the precise molecular mechanism of their interaction is still unknown. However, from a sequence alignment of KD2 with other members of the cystatin superfamily and from its inhibitory profile (Auerswald 
A

B
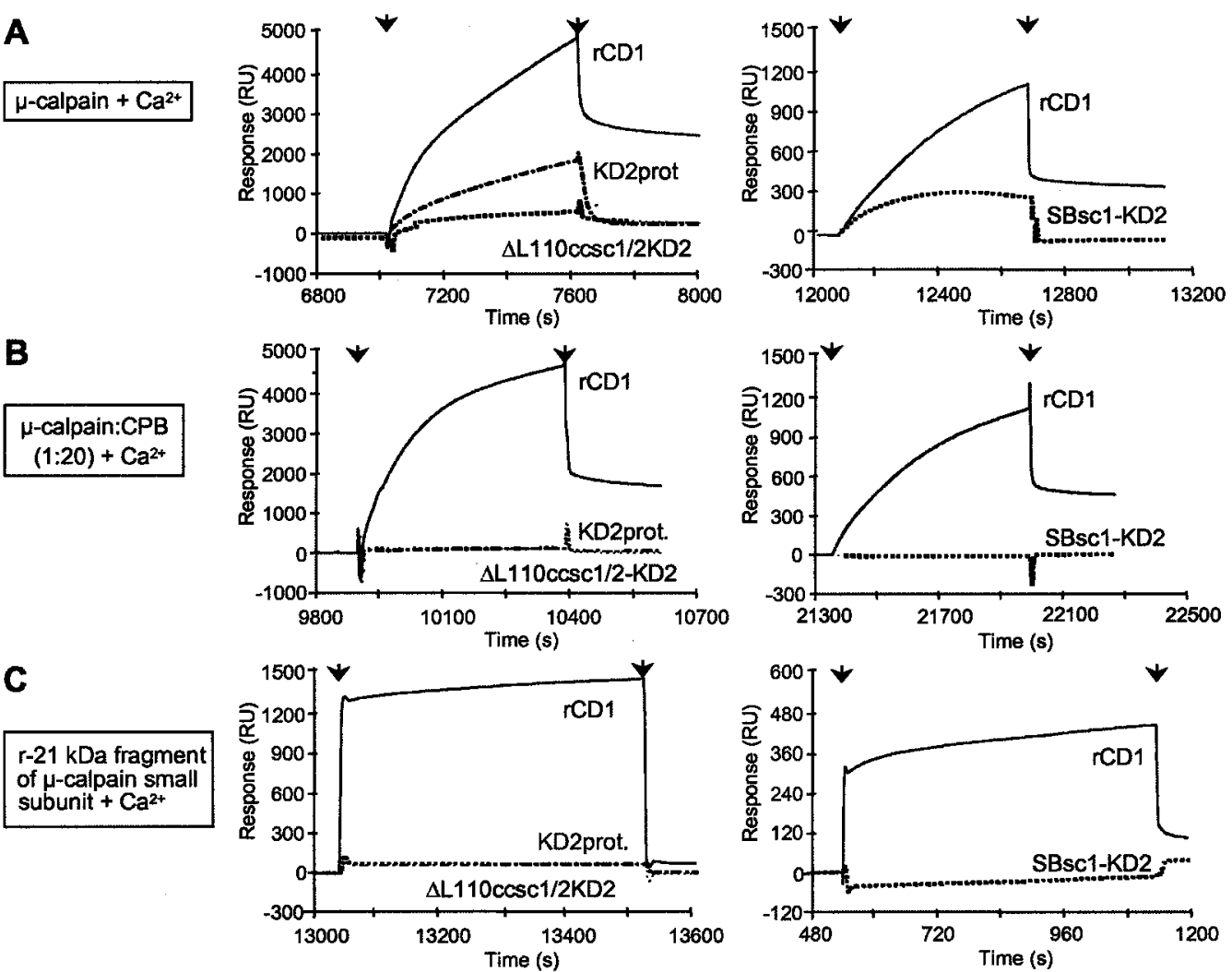

Fig. 6 Binding of $\mu$-Calpain to Immobilised Cystatin- und Calpastatin-Type Inhibitors.

Overlay plots of typical BIAcore sensorgrams showing the interaction of the immobilised inhibitors with injected $\mu$-calpain (A, B) and a recombinant fragment $(\mathrm{r}-21 \mathrm{kDa})$ of its small subunit $(C)$, respectively, in the presence of calcium ions. A preincubated mixture of $\mathrm{Ca}^{2+}$ activated $\mu$-calpain and calpastatin peptide B (CPB) was injected in competition experiments (B). The panels on the left side show sensorgrams obtained with a chip loaded with recombinant calpastatin domain 1 (rCD1, - ), kininogen domain 2 obtained by limited proteolysis (KD2 $\left.2_{\text {prot }},-\cdot-\right)$, and $\Delta$ L110ccsc1/2-KD2 (…). On the right side, sensorgrams of a second chip loaded with rCD1 (-) and SBsc1-KD2 (…) are displayed. Arrowheads indicate start (left) and end (right) of injections. The 'bulk' effect of buffer constituents was minimised by subtracting blank sensorgrams (not shown) obtained with immobilised chicken cystatin (left panels) or recombinant stefin B (right panels).

et al., 1996) we expect kininogen domain 2 to have a cystatin-like structure and thus to inhibit calpain by a similar molecular mechanism as it inhibits papain-like cysteine proteinases. Moreover, structural alignment of the catalytic domain (subdomains Ila and IIb) of m-calpain with papain suggested that the functional active site formed after calcium-triggered conformational changes should be similar to the active site of papain (Hosfield et al., 1999; Strobl et al., 2000).

Exchange of the papain-binding regions of chicken cystatin by the corresponding sequences of KD2 rendered chicken cystatin-KD2 hybrids that inhibited m-calpain with equilibrium dissociation constants $\left(K_{i}\right)$ in the higher nM range (Auerswald et al., 1996). In contrast to earlier results (Bradford et al., 1993), a contribution of all three binding regions of the cystatins to calpain inhibition could be demonstrated (Auerswald et al., 1996), leading us to the hypothesis that the interaction between KD2 and calpain closely resembles the interaction of cystatins with papain-like cysteine proteinases. Our results obtained with the stefin B-KD2 hybrid SBsc1-KD2 support this hypothesis. Stefin B belongs to family 1 of the cys- tatin superfamily (Turk and Bode, 1991) and differs from chicken cystatin (family 2) and KD2 (family 3 ) by its intracellular occurrence and lack of disulphide bridges. Its binding mode to cysteine proteinases is well documented by the crystal structure of a stefinB complex with carboxymethylated papain (Stubbs et al., 1990). In the present work, substitution of the N-terminal segment of stefin $B$ by the corresponding sequence of KD2 resulted in a $\mu$-calpain inhibitor with a $K_{\mathrm{i}}$ of $188 \mathrm{nM}$, suggesting that calpain inhibition is not dependent on the individual scaffold of kininogen domain 2 or chicken cystatin, but is rather due to the presence of calpain-binding sites which may be located within the contact regions of either a family 1 , family 2 or family 3 cystatin-fold. As the two Cys residues of the $\mathrm{N}$-terminal segment of KD2 were replaced by Ser and Ala in the SBsc1-KD2 hybrid, the N-terminal 'small' disulphide loop of KD2 seems to be no absolute requirement for calpain inhibition. The corresponding $\Delta \mathrm{L} 110 \mathrm{ccsc} 1 / 2-\mathrm{KD} 2$ hybrid containing these two cysteines is an only 6-fold more potent calpain inhibitor.

Examination of the inhibition profiles of the hybrids against papain and cathepsin $L$ (Table 2 ) reveals that the 
chimeric inhibitors inhibit these enzymes almost as efficiently as the parent molecules. This allows us to assume that the mutations did not significantly affect the general cystatin-like mode of interaction with papain-like cysteine proteinases, although they introduced the additional capability for calpain inhibition. The precise nature of the sequences required for calpain inhibition cannot be deduced from the limited number of hybrid proteins studied in this work, but the $\mathrm{N}$-terminal contact region seems to play a predominant role. New reports on cystatin $\mathrm{C}$ and $\mathrm{D}$ have indeed shown that the $\mathrm{N}$-terminal regions of cystatins are the most important determinants of inhibitory selectivity for individual papain-like proteinases (Mason et al., 1998). On the other hand, changes within the cystatin framework have been found to modulate inhibitory specificity and potency (Gerhartz et al., 1997; Hall et al., 1998). The latter observations are in accordance with our findings that deletion of the single Leu110 residue in the chicken cystatin-KD2 hybrids improved calpain inhibition 4 to 8-fold (see Table 2). Surprisingly, the very weak but significant $\mu$-calpain inhibition by wild-type chicken $\left(K_{\mathrm{i}}=\right.$ $75 \mu \mathrm{M}$ ) increased even 80 -fold after deletion of L110. Leu110 is not part of a contact region, but its deletion was expected to amend the misannealing of the putative c3 loop of KD2 to the chicken cystatin scaffold (Auerswald et al., 1996).

In contrast to the stable inhibition of calpain by KD2, it was found previously that all calpain-inhibiting chicken cystatin-KD2 hybrids were temporary inhibitors (Auerswald et al., 1996). In the present work we were able to show that this temporary inhibition is due to selective cleavage of a single peptide bond after the conserved Gly residue within the proposed $\mathrm{N}$-terminal binding regions of the chimeric inhibitors (corresponding to Gly9 in chicken cystatin and Gly4 in stefin B), resulting in N-terminally truncated inhibitors of much lower affinity. We have observed cleavage of the Gly9-Ala10 peptide bond by papain in previous work with deletion mutants of the first and second hairpin loop of chicken cystatin and explained it by substrate-like cleavage of the mutated inhibitors due to distorted binding in one of the two hairpin loop regions required for the formation of a stable complex (Auerswald et al., 1995; Machleidt et al., 1995). The fact that the recombinant chimeric calpain inhibitors, but not inhibitorily active KD2 (obtained by limited proteolysis of L-kininogen), are cleaved by calpain at the corresponding peptide bond allows three conclusions: (i) the cystatin-type calpain inhibitors interact with the active site of the catalytic subunit of calpain; (ii) their mode of interaction with calpain is similar to that of cystatins with papain-like cysteine proteinases; (iii) in contrast to natural KD2, the chimeric inhibitors fit imperfectly to the active site of calpain and are therefore slowly cleaved in a substrate-like manner. Attempts to generate permanent calpain inhibitors by modification of the cleavage site do not seem promising because mutations in the corresponding region of cystatin $\mathrm{C}$ have been shown to decrease its binding affinity for various cysteine proteinases (Björk et al., 1995).
Our initial hypothesis that the misalignment of the second disulphide loop of chicken cystatin with the corresponding part of KD2 might be responsible for the temporary calpain inhibition of the chicken cystatin-KD2 hybrids was not confirmed. Although calpain inhibition by all cc-KD2 $\Delta \mathrm{L} 110$ deletion mutants was slightly improved (see above), they remained temporary inhibitors. Like the chicken cystatin-KD2 hybrids, the stefin B-KD2 hybrid SBsc1-KD2 is also a temporary inhibitor of $\mu$-calpain. Sequence alignment of contact region $\mathrm{c} 3$ of stefin $\mathrm{B}$ with the corresponding KD2 region displays even greater differences than in the case of chicken cystatin. This may explain why the hybrids SBsc3-KD2 and SBsc1/3-KD2 were not expressed as soluble proteins in $E$. coliperiplasmic fractions, but appeared as inclusion bodies in the cytoplasm. The second hairpin loop region appears to play an important role in the maintenance of the overall three-dimensional structure.

For the first time, the binding of whole heterodimeric $\mu$-calpain to kininogen domain 2 and to calpain-inhibiting recombinant cystatin variants was investigated by real time biomolecular interaction analysis and compared with the binding of $\mu$-calpain to the inhibitory domain 1 of calpastatin. The most stringently conserved residues among the four repetitive calpastatin domains are not randomly distributed but cluster in three subdomains designated A, B and C within each domain (Maki et al., 1989). Structure-function analysis has revealed that region $B$ is essential for inhibition and that a 27-residue synthetic oligopeptide (calpastatin peptide B, CPB) comprising this region retains inhibitory activity in the low nanomolar range. In this work, we were able to show by real-time biomolecular interaction analysis that binding of $\mu$-calpain to kininogen domain 2 as well as to chicken cystatin-KD2 and stefin B-KD2 hybrids can be prevented by an excess of CPB. Competition of CPB with calpain substrates has been demonstrated previously by kinetic analysis using calpastatin fragments containing the region B (Maki et al., 1988; Kawasaki et al., 1989). Binding of peptide $B$ near the catalytic centre of calpain has further been supported by competition experiments using small inhibitors (Kawasaki et al., 1989; Crawford et al., 1993). Based on these earlier reports, our results strongly support the hypothesis that the cystatin-like inhibitors bind to the catalytic domain of calpain.

Conversely, binding of $\mu$-calpain to recombinant calpastatin domain 1 could not be prevented by CPB, indicating that additional binding sites are involved. These results agree with previously published BIAcore experiments demonstrating that non-inhibitory peptides derived from regions $A$ and $C$ of the calpastatin domain are able to bind the calmodulin-like domains of the large and of the small subunit of calpain, respectively (Takano et al., 1995). CaMLD binding and the degree of calpain inhibition have been demonstrated to be well correlated (Ma et al., 1994). Thus the tripartite subdomain structure of the inhibitory calpastatin domain (regions A, B and C) should contribute to the formation of a tight calpain-calpastatin 
complex (Takano et al., 1995). Neither kininogen domain 2 nor the chicken cystatin-KD2 and stefin B-KD2 hybrids contain putative calmodulin-binding motifs. Accordingly, we found that only calpastatin domain 1 but not the cystatin-type inhibitors were able to interact with the SCaMLD of the $21 \mathrm{kDa}$ fragment.

Although the interaction of cystatins with papain-like enzymes involves three main contact regions, these are known to form a wedge-like contiguous contact area binding to spatially closely related primed and nonprimed subsites of the enzymes (Bode et al., 1988). In contrast, the proposed tripartite nature of the calpastatin-calpain interaction would require simultaneous binding to the active site in domain Ila+llb as well as to both CaMLDs (domain IV and domain VI) located quite far apart from it (Hosfield et al., 1999; Strobl et al., 2000). Solution of the three-dimensional structures of calpain complexes with calpastatin domains and kininogen domain 2 remains a challenge for future investigations.

\section{Materials and Methods}

\section{Materials}

All chemicals used were purchased from Sigma (Deisenhofen, Germany), Merck (Darmstadt, Germany), Serva (Heidelberg, Germany) or Fluka (Buchs, Switzerland) and were of analytical grade. Restriction endonucleases and DNA modifying enzymes were from Roche Molecular Biochemicals (Mannheim, Germany) and New England Biolabs (Schwalbach, Germany). Human kininogen domain 2 obtained by limited proteolysis of human Lkininogen (Auerswald et al., 1996) was a generous gift from J. Brzin (Ljubljana, Slovenia). Recombinant human calpastatin domain 1 and calpastatin peptide $B$ (calpain inhibitor peptide) were purchased from Calbiochem (Bad Soden, Germany) and Sigma, respectively. Papain (EC 3.4.22.2) from Boehringer (Mannheim, Germany) was repurified and active-site titrated with E-64 as described previously (Barrett and Kirschke, 1981; Machleidt et al., 1995). Human cathepsin L (EC 3.4.22.15) and human L-kininogen were purchased from Calbiochem. Fluorogenic substrates Z-Phe-Arg-AMC, Bz-Arg-AMC and Suc-Leu-Tyr-AMC were obtained from Bachem (Heidelberg, Germany). All reagents and materials for biomolecular interaction analysis were from Biacore AB (Uppsala, Sweden).

\section{PCR Mutagenesis and Expression of $\Delta$ Leu 110 Chicken Cystatin-KD2Hybrids}

Plasmids containing the genes for chicken cystatin $r-c c$ and chicken cystatin-KD2 hybrids cc sc1/2-KD2, cc sc2/3-KD2 and cc sc1/2/3-KD2 (Auerswald et al., 1996) were used for construction of the corresponding $\Delta$ Leu 110-variants. The $\Delta$ Leu 110 chicken cystatin-KD2 hybrids were prepared by PCR mutagenesis using these plasmids as templates and the oligonucleotide primers CCAL110FO(5'-TGCACTGCAGGTTGAAATCGGTC-3'), CC $\triangle$ L110RE (5'-CCGCTCGAGTTTGATCTGGTTCAGCCACGG3'), and SC3 $\triangle$ L110RE (5'-CCGCTCGAGTTTAGCGATACGCAGCTGGAT-3'). The PCR products were ligated into the expression vector pIN-III-ompA2 after digestion with EcoRI and BamHI. Correct plasmids were selected after restriction analysis and DNA sequencing.
Synthesis, Cloning, Cassette Mutagenesis and Expression of Human StefinB and Stefin B-KD2 Hybrids

A synthetic gene for stefin B was designed using the GCG programme (HUSAR, Heidelberg, Germany) for editing DNA and amino acid sequences (Figure 2). The cDNA sequence for stefin B from GenBank (\#LO3558) served as a scaffold for design. Whenever possible, codons present in highly expressed genes of E.coli (Kane, 1995) were selected to ensure good levels of expression. At the 5' end of the gene an EcoRI restriction site was added and at the 3' end two stop codons and a HindIII restriction site were included in order to make a direct cloning into pUC 18 (cloning vector) and pASK 40 (expression vector) possible. New restriction sites were introduced without alteration of the amino acid sequence. Unique sites already present in the DNA sequence were left undisrupted and repeated sites were eliminated to allow cassette mutagenesis. Synthesis was basically performed according to (Khorana, 1979; Ferretti et al., 1986). The gene was divided into 12 oligonucleotides, which were purchased from MWG-Biotech (Ebersberg, Germany). Briefly, $200 \mathrm{pmol}$ of the internal oligonucleotides (SBwt-02, -03, -04, -05, -06, -07, -08, -09, -10, -11) were phosphorylated at their 5 ' ends. After phosphorylation, the internal oligonucleotides were mixed with 200 pmol of the external oligonucleotides (SBwt-01 and -12). This hybridisation mixture was incubated at $95^{\circ} \mathrm{C}$ during $5 \mathrm{~min}$ and cooled down overnight to room temperature. The internal nicks were subsequently ligated and the hybridisation product was purified by electrophoretic separation on a $2 \%$ low melting agarose gel. The DNA fragment was extracted from the gel and ligated in a molar ratio of $15: 1$ into a pUC 18 cloning vector previously digested with EcoRI and HindIII. Correct plasmids were selected after restriction analysis and DNA sequencing. The hybrid SBsc3-KD2 was synthesised in the same way as stefin $B$, replacing the oligos SBwt-09 and -10 by SBsc3-09 (5'-TGCGTGTTTTCCAGGACATCCAGCTGCGTATCGCTTCCAA-3') and SBsc3-10 (5'-AAGGTCCTGTAGGTCGACGCATAGCGAAGGTTGATGTCT3'). SBsc1-KD2 and SBsc1/3-KD2 were obtained by cassette mutagenesis. The new cassette sc1 (SBsc1-01: 5'-AATTCCGCTGAAGGTCCGGTTGTTACCGCTCAGTACGACTCCCTGGGTGCTGTTAGCGCTACCCAGCCGGCTACTGCA-3'; SBsc102: 5'-GGCGACTTCCAGGCCAACAATGGCGAGTCATGCTGA GGGACCCACGACAATCGCGATGGGTCGGCCGATG-3') carrying the sequence corresponding to the $\mathrm{N}$-terminus of $\mathrm{KD} 2$ was ligated into the plasmids containing the correct sequences for stefin B and SBsc3-KD2 after removing the original cassette by EcoRl/Pstl restriction digestion. For periplasmic expression in $E$. coli, the genes obtained by synthesis or by cassette mutagenesis were subcloned into pASK40 (Skerra et al., 1991) via the EcoRI/HindIII restriction sites. Recombinant strains, obtained by transformation of $\mathrm{JM} 83 \mathrm{E}$. coli competent cells with the plasmids carrying the correct sequences of stefin $B$ and stefin $B-K D 2$ hybrids were cultured at $37^{\circ} \mathrm{C}$ until $\mathrm{OD}_{550 \mathrm{~nm}}=0.6-0.8$ and induced, for heterologous expression, with 1 mM IPTG. The cells were grown 4 hours at $30^{\circ} \mathrm{C}$ and harvested by centrifugation (4000 g, $25 \mathrm{~min}$ ). Cell lysates were tested for expression by SDS-PAGE and Western blot analysis using polyclonal antibodies (rabbit) against human stefin B (DR Laboratories, Dießen) and POD-anti rabbit lgG (goat; Dianova, Hamburg).

\section{Isolation and Purification of the Recombinant Hybrids}

Periplasmic fractions were isolated according to (Dalböge et al., 1989) using a cold osmotic shock. Briefly, harvested cell pellets were washed with $1 / 5$ of the culture volume of chilled $200 \mathrm{mM}$ Tris/ $\mathrm{HCl}, 20 \%$ sucrose, $100 \mathrm{~mm}$ EDTA (pH 9.0) and were shaken on ice for about $10 \mathrm{~min}$. After centrifugation at $6000 \mathrm{~g}$ for $20 \mathrm{~min}$, 
the pellets were resuspended in $1 / 5$ of the culture volume of chilled $20 \mathrm{~mm}$ Tris/ $\mathrm{HCl}(\mathrm{pH} 7.5)$. Purification of the hybrids was achieved by affinity chromatography on a carboxymethyl-papain Sepharose column (Anastasi et al., 1983) followed by anion exchange chromatography on a Mono $Q$ column using a FPLC system.

\section{SDS-PAGE, HPLC, N-Terminal Amino Acid Sequencing and Mass Spectrometry}

SDS-PAGE of the recombinant hybrids was performed in $15 \%$ polyacrylamide gels according to Laemmli (1970). The homogeneity of the purified hybrids was checked by reversed-phase HPLC. Two nmol of each sample were applied to a Jupiter C4-column (150 x $1 \mathrm{~mm}$, Phänomenix, Aschaffenburg, Germany) and eluted with a linear gradient $(0-60 \%)$ of acetonitrile in $0.1 \%$ TFA using a flow rate of $60 \mu \mathrm{l} \cdot \mathrm{min}^{-1}$. The recombinant inhibitors were identified by $\mathrm{N}$-terminal amino acid sequencing with a gas-phase sequenator 473A (Applied Biosystems, Weiterstadt, Germany) according to the instructions of the manufacturer. The molecular masses of the inhibitors were determined by mass spectrometry using a tandem quadrupole ionspray mass spectrometer API III (Sciex Thornhill, Ontario, Canada) basically as described elsewhere (Covey et al., 1988; Mann et al., 1989).

\section{Inhibition Assays and Determination of Kinetic Constants}

Inhibition of papain and cathepsin $L$ was assayed at $30^{\circ} \mathrm{C}$ and $\mathrm{pH} 5.5$ with the fluorogenic substrate Z-Phe-Arg-NH-Mec as described in detail elsewhere (Machleidt et al., 1993, 1995). Inhibition of $\mu$-calpain $(5-10 \mathrm{~nm})$ was measured in continuous fluorimetric assays at $12{ }^{\circ} \mathrm{C}$ (to slow down inactivation due to autolysis) in $50 \mathrm{~mm}$ Tris/HCl, pH 7.5, $100 \mathrm{~mm} \mathrm{NaCl}, 0.015 \%$ Brij$35,100-150 \mu \mathrm{M} \mathrm{CaCl}_{2}$, and $1 \mathrm{~mm}$ dithiothreitol (freshly added) in a total volume of $500 \mu \mathrm{l}$ using the fluorogenic substrate Suc-LeuTyr-AMC $(250 \mu \mathrm{M})$. After a constant reaction rate was achieved (10-20 $\mathrm{min}$ ), the inhibitors were added and the reaction was followed towards a stable equilibrium (15-90 $\mathrm{min}$ ). The rate constants $k_{\text {on }}$ and $k_{\text {off }}$ for complex formation of cathepsin L, papain and calpain with L-kininogen, kininogen domain 2 and the hybrids were obtained by presteady-state analysis of the progress curves (Morrison, 1982). Equilibrium dissociation constants $\left(K_{i}\right)$ were calculated from the rate constants $\left(K_{\mathrm{i}}=k_{\text {off }} / k_{\text {on }}\right)$ or, for some calpain inhibitors with very low affinity, measured directly in steady-state experiments, and were corrected for competition of the inhibitor with the substrate. The inhibitorily active concentrations of inhibitors were determined by titration with E-64standardised papain (4 nM) using the substrate Bz-R-NH-Mec (10 $\mu \mathrm{M})$ (Barrett and Kirschke, 1981).

\section{Isolation of $\mu$-Calpain from Human Erythrocytes}

Human $\mu$-calpain (EC 3.4.22.17) was isolated from erythrocytes following a protocol established in our laboratory (D. GabrijelcicGeiger and E. A. Auerswald, unpublished). Briefly, after lysis of erythrocytes and centrifugation, the supernatant was applied to a DEAE-Sepharose ion-exchange column. Bound fractions were eluted and further purified on Phenyl-Sepharose (separation of calpastatin from calpain). Enzymatically active fractions were applied to gel filtration on Superdex-200 and finally purified on Blue-Sepharose. The final product was homogeneous $(80 \mathrm{kDa}$ and $30 \mathrm{kDa}$ subunits) and more than $95 \%$ pure as judged by SDS-PAGE and $\mathrm{N}$-terminal sequence analysis. Average yields were about $2 \mathrm{mg}$ of purified $\mu$-calpain from $600 \mathrm{ml}$ erythrocyte concentrate.

\section{Cloning, Expression and Purification of a 21 kDa Calpain Small Subunit Fragment}

A C-terminal fragment $(21 \mathrm{kDa})$ comprising residues $86-268$ (preceded by Met) was created by cloning the PCR product of the cDNA of the calpain $30 \mathrm{kDa}$ subunit (kindly provided by $\mathrm{K}$. Suzuki (Institute of Molecular and Cellular Bioscience, University of Tokyo, Japan) into a pET-22b(+) vector. Expression was achieved under the control of the T7 promotor in E. coli BL384, rendering yields of about $15 \mathrm{mg} / \mathrm{l}$ cell culture. The recombinant $21 \mathrm{kDa}$ protein carrying a C-terminal $\mathrm{His}_{6}-\mathrm{Tag}$ was isolated from the soluble fraction of cell lysates and purified by affinity chromatography on a Ni-NTA column. This procedure provided a $>90 \%$ pure protein according to SDS-PAGE, $\mathrm{N}$-terminal sequencing and mass spectrometry.

\section{Biomolecular Interaction Analysis}

Real-time biomolecular interaction analysis was performed using surface plasmon resonance technology in a BIAcore 2000 instrument (Biacore $A B$ ). The inhibitors were immobilised on CM5 chips via amine group coupling. After activation of the sensor chips with $35 \mu \mathrm{l} 0.05 \mathrm{M} \mathrm{N}$-hydroxysuccinimide and $0.2 \mathrm{M} \mathrm{N}$-ethyl- $\mathrm{N}$-[3-(diethylamino)propyl]carbodiimide (flow rate $\left.5 \mu \mathrm{l} \cdot \mathrm{min}^{-1}\right), 35 \mu \mathrm{l}$ of the inhibitor solutions $\left(25-100 \mu \mathrm{g} \cdot \mathrm{ml}^{-1}\right.$ in $10 \mathrm{~mm}$ sodium acetate, $\mathrm{pH} 4.2$ ) were injected, followed by $35 \mu \mathrm{l}$ of $1.0 \mathrm{M}$ ethanolamine $(\mathrm{pH} 8.5)$ for deactivation of unreacted groups. HBS buffer (Biacore) was used as running buffer throughout the coupling procedure. After coupling, the chip was washed with $3.0 \mathrm{M} \mathrm{NaCl}, 0.1 \mathrm{M} \mathrm{NaOH}$ to remove non-covalently bound ligands. Binding experiments were performed at $25^{\circ} \mathrm{C}$ in $50 \mathrm{~mm}$ Tris $/ \mathrm{HCl}, 100 \mathrm{~mm} \mathrm{NaCl}, 0.015 \%$ Brij35, pH7.5, as running buffer by injecting the analyte solutions $\left(5-100 \mu \mathrm{g} \cdot \mathrm{ml}^{-1}\right)$ over $10 \mathrm{~min}$ with a flow rate of $5 \mu \mathrm{l} \cdot \mathrm{min}^{-1}$. The surface was regenerated between cycles by injecting $25 \mu$ of $3.0 \mathrm{M} \mathrm{NaCl}, 0.1 \mathrm{M} \mathrm{NaOH}$.

\section{Acknowledgements}

The authors wish to thank Mrs. H. Hinz, Mrs. C. Huber, Mrs. B. Meisel and Mrs. R. Zauner for excellent technical assistance. The amino acid sequencing and mass spectrometry work of Mr. R. Mentele performed in the laboratory of Prof. F. Lottspeich, Martinsried, is gratefully acknowledged. We thank Prof. K. Suzuki (Institute of Molecular and Cellular Bioscience, University of Tokyo, Japan) for kindly providing the cDNA of the calpain small subunit. The work was supported by a grant of the Deutscher Akademischer Austauschdienst (DAAD) to B. García Díaz and by the Sonderforschungsbereich 469 of the Ludwig-MaximiliansUniversität München (grants A-2/Machleidt, A-3/Auerswald).

\section{References}

Anastasi, A., Brown, M. A., Kembhavi, A. A., Nicklin, M. J., Sayers, C. A., Sunter, D. C. and Barrett, A. J. (1983). Cystatin, a protein inhibitor of cysteine proteinases. Improved purification from egg white, characterization, and detection in chicken serum. Biochem. J.21, 129-138.

Auerswald, E. A., Nägler, D. K., Assfalg-Machleidt, I., Stubbs, M. T., Machleidt, W. and Fritz, H. (1995). Hairpin loop mutations of chicken cystatin have different effects on the inhibition of cathepsin B, cathepsin L and papain. FEBS Lett. 361, 179-184.

Auerswald, E. A., Nägler, D. K., Gross, S., Assfalg-Machleidt, I., Stubbs, M. T., Eckerskorn, C., Machleidt, W. and Fritz, H. (1996). Hybrids of chicken cystatin with human kininogen do- 
main 2 sequences exhibit novel inhibition of calpain, improved inhibition of actinidin and impaired inhibition of papain, cathepsin L and cathepsin B. Eur. J. Biochem. 235, 534-542.

Barrett, A. J. and Kirschke, H. (1981). Cathepsin B, Cathepsin H, and cathepsin L. Meth. Enzymol. 80, 535-561.

Björk, I., Brieditis, I. and Abrahamson, M. (1995). Probing the functional role of the $\mathrm{N}$-terminal region of cystatins by equilibrium and kinetic studies of the binding of Gly-11 variants of recombinant human cystatin $\mathrm{C}$ to target proteinases. Biochem. J. 306, 513-518.

Blanchard, H., Grochulski, P., Li, Y., Arthur, J. S., Davies, P. L., Elce, J. S. and Cygler, M. (1997). Structure of a calpain $\mathrm{Ca}^{2+}$ binding domain reveals a novel EF-hand and $\mathrm{Ca}^{2+}$-induced conformational changes. Nature Struct. Biol. 4, 532-538.

Bode, W., Engh, R., Musil, D., Thiele, U., Huber, R., Karshikov, A., Brzin, J., Kos, J. and Turk, V. (1988). The $2.0 \AA$ X-ray crystal structure of chicken egg white cystatin and its possible mode of interaction with cysteine proteinases. EMBO J. 7, 2593-2599.

Bradford, H. N., Jameson, B. A., Adam, A. A., Wassell, R. P. and Colman, R. W. (1993). Contiguous binding and inhibitory sites on kininogens required for the inhibition of platelet calpain. J. Biol. Chem. 268, 26546-26551.

Carafoli, E. and Molinari, M. (1998). Calpain: a protease in search of a function? Biochem. Biophys. Res. Commun. 247, 193-203.

Covey, T. R., Bronner, R. F., Shushan, B. I. and Henion, J. (1988). The determination of protein, oligonucleotide and peptide molecular weights by ion-spray mass spectrometry. Rapid Commun. Mass. Spectrom. 2, 249-256.

Crawford, C. (1987). Inhibition of chicken calpain II by proteins of the cystatin superfamily and alpha 2-macroglobulin. Biochem. J. 248, 589-594.

Crawford, C., Brown, N. R. and Willis, A. C. (1993). Studies of the active site of $\mathrm{m}$-calpain and the interaction with calpastatin. Biochem. J. 296, 135-142.

Dalböge, H., Jensen, E. B., Tottrup, H., Grubb, A., Abrahamson, M., Olafsson, I. and Carlsen, S. (1989). High-level expression of active human cystatin C in Escherichia coli. Gene 79, $325-332$.

Emori, Y., Kawasaki, H., Imajoh, S., Minami, Y. and Suzuki, K. (1988). All four repeating domains of the endogenous inhibitor for calcium- dependent protease independently retain inhibitory activity. Expression of the cDNA fragments in Escherichia coli. J. Biol. Chem. 263, 2364-2370.

Ferretti, L., Karnik, S. S., Khorana, H. G., Nassal, M. and Oprian, D. D. (1986). Total synthesis of a gene for bovine rhodopsin. Proc. Natl. Acad. Sci. USA 83, 599-603.

Gerhartz, B., Engh, R. A., Mentele, R., Eckerskorn, C., Torquato, R., Wittmann, J., Kolb, H. J., Machleidt, W., Fritz, H. and Auerswald, E. A. (1997). Quail cystatin: isolation and characterisation of a new member of the cystatin family and its hypothetical interaction with cathepsin B. FEBS Lett. 412, 551-558.

Hall, A., Ekiel, I., Mason, R. W., Kasprzykowski, F., Grubb, A. and Abrahamson, M. (1998). Structural basis for different inhibitory specificities of human cystatins $C$ and D. Biochemistry 37 , 4071- 4079 .

Hosfield, C. M., Elce, J. S., Davies, P. L. and Jia, Z. (1999). Crystal structure of calpain reveals the structural basis for $\mathrm{Ca}(2+)-$ dependent protease activity and a novel mode of enzyme activation. EMBO J. 18, 6880-6889.

Kane, J. F. (1995). Effects of rare codon clusters on high-level expression of heterologous proteins in Escherichia coli. Curr. Opin. Biotechnol. 6, 494-500.

Kawasaki, H., Emori, Y., Imajoh-Ohmi, S., Minami, Y. and Suzu$\mathrm{ki}, \mathrm{K}$. (1989). Identification and characterization of inhibitory sequences in four repeating domains of the endogenous inhibitor for calcium-dependent protease. J. Biochem. (Tokyo) 106, $274-281$.

Khorana, H. G. (1979). Total synthesis of a gene. Science 203, 614-625.

Laemmli, U. K. (1970). Cleavage of structural proteins during the assembly of the head of bacteriophage T4. Nature 227, 680-685.

Lin, G. D., Chattopadhyay, D., Maki, M., Wang, K. K., Carson, M., Jin, L., Yuen, P. W., Takano, E., Hatanaka, M., DeLucas, L. J. and Narayana, S. V. (1997). Crystal structure of calcium bound domain VI of calpain at $1.9 \AA$ resolution and its role in enzyme assembly, regulation, and inhibitor binding. Nature Struct. Biol. 4, 539-547.

Ma, H., Yang, H. Q., Takano, E., Hatanaka, M. and Maki, M. (1994). Amino-terminal conserved region in proteinase inhibitor domain of calpastatin potentiates its calpain inhibitory activity by interacting with calmodulin-like domain of the proteinase. J. Biol. Chem.269, 24430-24436.

Machleidt, W., Assfalg-Machleidt, I. and Auerswald, E. A. (1993). Kinetics and molecular mechanism of inhibition of cysteine proteinases by their protein inhibitors. In: Innovations in Proteases and their Inhibitors, F. X. Aviles, ed., (Berlin, Germany: Walter de Gruyter), pp. 179-196.

Machleidt, W., Nägler, D. K., Assfalg-Machleidt, I., Stubbs, M. T., Fritz, H. and Auerswald, E. A. (1995). Temporary inhibition of papain by hairpin loop mutants of chicken cystatin. Distorted binding of the loops results in cleavage of the Gly(9)-Ala(10) bond. FEBS Lett. 361, 185-190.

Maki, M., Takano, E., Mori, H., Sato, A., Murachi, T. and Hatanaka, M. (1987). All four internally repetitive domains of pig calpastatin possess inhibitory activities against calpains I and II. FEBS Lett. 223, 174-180.

Maki, M., Takano, E., Osawa, T., Ooi, T., Murachi, T. and Hatanaka, M. (1988). Analysis of structure-function relationship of pig calpastatin by expression of mutated cDNAs in Escherichia coli. J. Biol. Chem. 263, 10254-10261.

Maki, M., Bagci, H., Hamaguchi, K., Ueda, M., Murachi, T. and Hatanaka, M. (1989). Inhibition of calpain by a synthetic oligopeptide corresponding to an exon of the human calpastatin gene. J. Biol. Chem. 264, 18866-18869.

Mann, M., Meng, C. K. and Fenn, F. B. (1989). Interpreting mass spectra of multiply charged ions. Anal. Chem. 61, $1702-1708$.

Mason, R. W., Sol-Church, K. and Abrahamson, M. (1998). Amino acid substitutions in the $\mathrm{N}$-terminal segment of cystatin $\mathrm{C}$ create selective protein inhibitors of lysosomal cysteine proteinases. Biochem. J. 330, 833-838.

Morrison, J. F. (1982). The slow-binding and slow, tight-binding inhibition of enzyme-catalysed reactions. Trends Biochem. Sci. 7, 102-105.

Salvesen, G., Parkes, C., Abrahamson, M., Grubb, A. and Barrett, A. J. (1986). Human low-Mr kininogen contains three copies of a cystatin sequence that are divergent in structure and in inhibitory activity for cysteine proteinases. Biochem. J. 234, 429-434.

Skerra, A., Pfitzinger, I. and Plückthun, A. (1991). The functional expression of antibody Fv fragments in Escherichia coli: improved vectors and a generally applicable purification technique. Biotechnology 9, 273-278.

Sorimachi, H., Ishiura, S. and Suzuki, K. (1997). Structure and physiological function of calpains. Biochem. J. 328, 721-732.

Strobl, S., Fernandez-Catalan, C., Braun, M., Huber, R., Masumoto, H., Nakagawa, K., Irie, A., Sorimachi, H., Bourenkow, G., Bartunik, H., Suzuki, K. and Bode, W. (2000). The crystal structure of calcium-free human $\mathrm{m}$-calpain suggests an elec- 
trostatic switch mechanism for activation by calcium. Proc. Natl. Acad. Sci. USA 97, 588-592.

Stubbs, M. T., Laber, B., Bode, W., Huber, R., Jerala, R., Lenarcic, B. and Turk, V. (1990). The refined $2.4 \AA$ X-ray crystal structure of recombinant human stefin $B$ in complex with the cysteine proteinase papain: a novel type of proteinase inhibitor interaction. EMBO J. 9, $1939-1947$.

Suzuki, K. and Sorimachi, H. (1998). A novel aspect of calpain activation. FEBS Lett. 433, 1-4.

Takano, E., Ma, H., Yang, H. Q., Maki, M. and Hatanaka, M. (1995). Preference of calcium-dependent interactions be- tween calmodulin-like domains of calpain and calpastatin subdomains. FEBS Lett. 362, 93-97.

Turk, V. and Bode, W. (1991). The cystatins: protein inhibitors of cysteine proteinases. FEBS Lett. 285, 213-219.

Uemori, T., Shimojo, T., Asada, K., Asano, T., Kimizuka, F., Kato, I., Maki, M., Hatanaka, M., Murachi, T., Hanzawa, H. and et al. (1990). Characterization of a functional domain of human calpastatin. Biochem. Biophys. Res. Commun. 166, $1485-1493$

Received October 23, 2000; accepted November 8, 2000 